ULSC \#761903, VOL 35, ISS 2

\title{
Social Stratification and Sports' Participation in England
}

\section{PAUL WIDDOP AND DAVID CUTTS}

\section{QUERY SHEET}

This page lists questions we have about your paper. The numbers displayed at left can be found in the text of the paper for reference. In addition, please review your paper as a whole for correctness.

Q1. Au: Please clarify author names for Van Eijck et al. 2002. Are there 3 authors here or two?

Q2. Au: Wilson 2002 is not mentioned in the text. Please cite in text or delete from References.

\section{TABLE OF CONTENTS LISTING}

The table of contents for the journal will list your paper exactly as it appears below:

Social Stratification and Sports' Participation in England

Paul Widdop and David Cutts 


\title{
Social Stratification and Sports' Participation in England
}

\author{
PAUL WIDDOP \\ Institute for Social Change \\ University of Manchester \\ Manchester, England

\section{DAVID CUTTS} \\ Department of Politics, Languages, and International Studies \\ University of Bath \\ Bath, England
}

Using a latent class analysis, we identify distinct typologies of sports' consumers in England and then determine whether the socio-economic makeup of the latent classes resemble recent scholarly work across different cultural and leisure fields. The third part of the analysis provides a nuanced rigorous statistical evaluation of the subtle socio-economic differences between the active sports' clusters. Our analysis is unique with few studies, if any, identifying and then examining types of sports consumers in this way. The findings largely corroborate research in other cultural and leisure fields, although there are distinctive types of consumers' specific to sport along gender lines, and a group which consumes highbrow sports but when compared to other types of sports' consumers, do not exclusively come from the higher social strata.

Keywords fitness, highbrows, omnivores, sport consumption, social stratification

\section{Introduction}

On July 6, 2005, the International Olympic Committee awarded the right to stage the 2012 summer Olympic and Paralympic Games to London. The scenes of celebration that greeted the announcement reflected the cultural and economic centrality of sport in Britain. Sport is big business and borderless in its scope of enjoyment and participation. It provides important positive benefits in numerous policy arenas: education, social cohesion, community regeneration, the environment, physical and mental health and wellbeing to name a few (Downward, Lera-Lopez, \& Rasciute, 2011). While sport has been studied more broadly in other scholarly fields such as economics, marketing, medicine (Downward, et al.), the social inequalities associated with cultural capital in England remains largely overlooked (Washington \& Karen, 2001; Warde, 2006).

In the leisure participation field, the basic social and cultural structure could be summarized on the basis of dichotomies - refined and vulgar, active and passive, public and

25 commercial. Individuals on high income and/or education differentiate themselves from those lower on the social hierarchy by consuming more complex, prestigious, refined forms

Received 8 November 2011; accepted 1 November 2012.

Address correspondence to David Cutts, Department of Politics, Languages, and International Studies, University of Bath, 1 West North, Bath, BA2 7AY, UK. E-mail: d.j.cutts@bath.ac.uk 
of leisure (Mommaas, 1997; Van Eijck \& Mommaas, 2004). Yet it was Bourdieu (1984) who provided the most comprehensive theory of the interrelationship between cultural and social hierarchies. For Bourdieu, those belonging to the dominant or bourgeoisie classes affirm their higher social status through the appreciation and consumption of highbrow or legitimate culture. Such people have more cultural capital than lower status groups (Van Eijck, 2001). The existence of a relationship between the cultural field, where a range of cultural activities can be positioned, and the social field, in which participants occupy their particular social position, became the orthodoxy for 20 years or more (Chan, 2010).

However, growing skepticism about whether Bourdieu's theoretical framework could be likened to contemporary social reality led some to question the relationship between so-called legitimate or highbrow culture and high social status (Peterson \& Simkus, 1992; Van Eijck, 1997, 2001). Since the 1990s, empirical research began to demonstrate that the socio-cultural reality was different from the one depicted by Bourdieu (Peterson \& Simkus; Peterson \& Kern, 1996). Numerous studies found that most members of the high social strata regularly consumed popular culture, while consumption patterns for those among the lower social strata tended to be more restricted to the popularized forms (Van Eijck, 1997; Peterson \& Simkus). Peterson (1992) labeled these higher status groups as "omnivorous," with an openness to appreciate a wide variety of cultural items from which tastes and consumption may or may not develop. He labeled those in the lower status groups as univorous because they remain oriented to one or a limited number of popular aesthetic traditions (Peterson, 1992; Peterson \& Kern, 1996). Omnivorous individuals are not necessarily high cultural consumers but partake in a diversity of leisure and culture expressions, which generates a broad cultural knowledge and can be a valuable social resource (Peterson \& Kern; Stalker, 2011). As Stalker notes, "through their leisure, omnivores are able to participate in and discuss broad leisure pursuits that can range in a commitment from serious leisure (Stebbins, 1992) to popular culture and commercial leisure services with mass appeal."

Scholarly studies of cultural consumption in England have engaged in similar debates about cultural omnivorousness across a range of fields, including music, visual art, museums and theatre, dance, and cinema attendance (Bennett et al., 2009; Warde, Wright, \& Gayo-Cal, 2008; Chan \& Goldthorpe, 2005, 2007). Yet sport as a form of cultural consumption, at least in England, has mostly been ignored (Warde, 2006). Here we seek to redress this imbalance. The purpose of this article is twofold. First, we examine how consumption of sport is related to social status in England. Do consumption patterns adhere to Bourdieu's theory, or do sport consumption patterns reflect different omnivore groups? If so, do these omnivore groups vary in their breadth of consumption? Do they differ from a traditional highbrow group from the higher social strata who only engage in "exclusive" sports? Second, we examine whether other indicators of stratification including age, gender, ethnicity, marital status, tenure, and the socio-economic composition of residence influences sport consumption patterns. Here we use a multiple indicator multiple cause model (MIMIC) to differentiate between distinct classes, and to assess how multiple axes of stratification are related to these patterns of sport consumption.

\section{From "Distinction" to "Omnivorism"}

Bourdieu's theoretical framework is based on the premise that homology ${ }^{1}$ and habitus $^{2}$ structure cultural consumption, and lifestyles create distinction in cultural practices. 1984).

${ }^{1}$ Homology is the relationship between social class position and cultural consumption (Bourdieu,

${ }^{2}$ Habitus is a set of dispositions which generate practices and perceptions, through socialization and education (Bourdieu, 1984). 
Individuals' tastes, judgments, and preferences for culture, leisure, and sport are determined by their position in the class structure, which reflects the composition and differing levels of social, economic, and cultural capital (Chan, 2010). Those individuals from the higher social classes share the tastes of members of their own class, and consume symbolically

75 selective activities (elite or high culture) that reinforce their class position. They also share their own class members' distastes. It is this reciprocity of tastes and distastes that reinforce the social and cultural hierarchy of consumption patterns. For instance, sport, like any other cultural practice, is an object of struggles between the social classes (Bourdieu, 1984). Participating in and consuming certain sports is a function of "distinction" that reaffirms

80 class position. According to Bourdieu, people participate in sports such as tennis, water sports, and golf partly due to gains in "distinction" that they bring. Differences in engaging in sport are therefore a function of cultural capital and class based habitus (Warde, 2006).

Bourdieu defines habitus as class specific dispositions inculcated in family, social networks, neighborhood, and educational institutions but is manifested in different individual

85 expressions (Bourdieu, 1984). It is generated by internalizing the social structural norms of ones' social status, which includes certain cultural forms and sports (Bennett et al., 2009). The habitus organizes how an individual classifies the range of consumption objects to which they are exposed, constructing desire toward consecrated objects (those that are desired by the middle and upper class) and disgust toward objects that are not valued (often

90 those cultural items enjoyed by the working classes/or popular culture).

Empirical doubts have been raised, however, about the validity of Bourdieu's theory. Many critics claim that his definition of cultural capital reflects both the time and place (mid-1960s France) in which the empirical study took place (Van Eijck, 1999; Holt, 1997). Others have claimed that research in other countries (even France itself) show a more

95 diversified cultural and leisure climate, with those in the higher social strata possessing a broader cultural repertoire, including popular culture consumption and participation in diverse leisure activities (Stichele \& Laermans, 2006; Mommaas, Van der Poel, Bramham, \& Henry, 1996).

Since the 1990s, a new theoretical framework has developed from empirical research

100 originating in the United States but now replicated worldwide. When examining the relationship between status hierarchy and cultural taste, researchers have found that high status groups had a broader cultural repertoire that included middlebrow and lowbrow activities, whereas lower status groups restricted their consumption patterns to mainstream or popular culture (Peterson \& Simkus, 1992; Peterson \& Kern, 1996). Based on these findings, those

105 individuals in the higher social strata who had an openness to appreciate everything from which consumption or tastes may or may not develop were labeled "omnivores" while those in the lower status groups were defined as "univores" (Peterson \& Simkus; Peterson, 2005; Chan, 2010). Since Peterson's groundbreaking work in the early 1990s, most scholars have observed the existence of an omnivore group which is often small in number and contains

110 individuals with high levels of education (Robinson, 1993; Van Eijck, 1999; Stichele \& Laermans, 2006). Social mobility across different social strata over recent decades has resulted in greater socio-cultural heterogeneity (Van Eijck, 1999; Peterson, 2005). Today's omnivores benefit from a broader and more diverse social network where they can display knowledge gained from interaction in different social circles, which reinforces social

115 approval within these new circles (Erikson, 1996; Van Eijck, 1999). Along with increasing social mobility, easier access to education, the advancement in online technology and development of the leisure industry, elite tastes have become more accessible to a wider segment of the population, thereby devaluing them as markers of exclusion (Peterson, 2005; Stichele \& Laermans). The leisure field has also become more open with the introduction 120 of new cultural pursuits and leisure activities following the continued growth of global 
cultural flows such as tourism, online media and through increasing geographic migration (Van Eijck \& Mommaas, 2004).

While omnivore-univore arguments clearly pose a challenge to Bourdieu's framework, the significance and meaning of Peterson's notion of cultural omnivorousness has itself been the subject of scholarly debate. Empirical research by leading cultural scholars have shown that it is important not to assume that appreciating several types of cultural genres or activities is limited to higher status groups (Van Eijck, 1999), or to confound omnivorousness for tastes with highbrow forms (Peterson, 2005). Increasingly, researchers have also found that omnivores may still exclude or discriminate against some forms of mass or popular culture (Peterson, 2005). Others claim there are different types of omnivores 130 in some leisure and cultural fields (Van Eijck \& Lievens, 2008; Sintas \& Alverez, 2004). Some note a number of 'partial' omnivore types existing on different scales of omnivorism (Emmison, 2003). There is also growing recognition that among high status groups there are both distinctive highbrow and omnivorous patterns (Van Eijck, 2001; Peterson, 2005). This has led to a refinement of the omnivore and univore dichotomy from what was origi- $\mathbf{1 3 5}$ nally depicted (Peterson, 2005). For instance, the small minority in the higher social strata who reject popular culture have been categorized as "highbrow univores" as opposed to the "highbrow omnivores" with similar categorizations for "lowbrow" groups (Peterson \& Rossman, 2007; Sonnett, 2004). Consequently, questions about how cultural omnivorousness is defined, measured, and operationalized remains the focus of much debate (Warde \& Gayo-Cal, 2009; Berghman \& Van Eijck, 2009).

\section{Cultural Capital and Sport}

In the field of sport, many leisure and cultural scholars have used Bourdieu's framework to examine how sports operate as cultural capital (Taks, Renson, \& Vanreusel, 1995; White \& Wilson, 1999; Thrane, 2001). For instance, one group of scholars examined how much class distinction operates in sports and found that monetary cost is only weakly associated with the class status of sports consumed (Taks et al.). Others have found that those richest in cultural capital (measured by educational attainment) are more involved in sports and that sports are part of the lifestyle clusters of the dominant classes (White \& Wilson). Another study found that the relationship between sport and educational achievement may depend not only on the cultural resources students bring to the school setting but also the on particular sporting activities in which students engage (Eitle \& Eitle, 2002). For instance, cultural disadvantage was found to contribute to heightened interest in basketball and football as an expression of social capital (Eitle \& Eitle).

Scholars have also noted that sport participation is positively associated with sport spectatorship and moderate participation in other highbrow cultural fields such as attending museums and classical music concerts (Thrane, 2001). This apparent shift from highbrow snobs to omnivores in the sport field (Stempel, 2005), however, remains underexplored in England (Warde, 2006). One U.S. study has shown that dominant class adults play 160 a wide range of sports, including popular mainstream sports, as much or more than the lower classes. The only exception was bowling, where participation rates are higher among the middle classes than the upper class (Stempel). There was also some evidence of cultural distancing, with upper classes engaging in aerobic sports and competitive sports to distinguish themselves from the lower and middle classes who adopt a less physically $\mathbf{1 6 5}$ strenuous lifestyle (Stempel; Wouters, 1998). A UK study found that the most privileged people choose exclusive sports, such as racket sports, water sports, and adventure sports and that the frequency of exercise and sporting participation was strongly related to social 
class (Warde, 2006). However, as in the United States and Australia (Stempel; Bennett,

170 Emmison, \& Frow, 1999), educated middle class people were more likely to engage in extensive physical activity and body maintenance (Warde, 2006). Gender also matters. Women (particularly middle class women) in the United Kingdom were more likely than men to participate in physical exercise (Warde). However, their range of participation in sporting activities was narrower than men.

\section{Overview of the Research Questions}

Based on existing literature on sport participation, and in light of scholarly refinements to the omnivore-univore dichotomy, we expected our analysis to find distinct typologies of sport consumers. However, whether the sporting lifestyle types identified are similar or distinct from other cultural and leisure fields remains uncertain. This is the focus of the first

180 part of the analysis and provides a number of research questions. For instance, as in other cultural fields such as music, will there be partial omnivore types of sports' consumers? If so, to what extent do these omnivore groups vary in their breadth of consumption? Given the work of Peterson (2005), we would expect that one omnivore group would participate in all types of sports at a greater volume and range than any other cluster. We might also expect

185 some individuals to have moderate levels of participation in exclusive sports-adventure sports, water sports, etc.- - but have a tendency to consume more popular sporting activities. Given the findings of Warde (2006), will we identify one active cluster whose individuals largely engage in physical activity-aerobic and/or fitness based sports-for both body maintenance and general fitness? Finally, there is some evidence in other cultural and leisure

190 fields, that among high status groups, there are both distinctive highbrow and omnivorous patterns (Peterson \& Rossman, 2007; Van Eijck, 2001). Given this, we might expect some individuals to be members of a highly cultured sporting group which participates exclusively in highbrow as opposed to more popularized sporting activities.

The second part of the analysis concerns the socio-economic makeup of each sport

195 cluster and examines the influence of class, education, and other stratification variables on cluster membership. Existing empirical findings suggest that higher education, higher income, and higher occupational status are strongly associated with omnivorous cultural and leisure preferences (Van Eijck, 2001; Sintas \& Alvarez, 2004; Stalker, 2011). Yet while some high status group members may share broader omnivorous taste patterns, to what extent

200 will others remain more exclusive in their preference, preferring those cultural objects most associated with the middle and upper classes? There is also growing scholarly evidence that body maintenance and physical activity are differentiated by class and education (Bennett et al., 1999; Washington \& Karen, 2001; Warde, 2006). If so, can we confirm that class and education are key drivers for those who have been shown to have a distinctive attitude

205 toward exercise, appearance, and the general maintenance of a healthy body? Are those who engage in a wide range of sports but largely consume popular sporting activities with mass appeal likely to be those from the lower social strata with more moderate levels of educational attainment?

Apart from class and education, how important are other stratification variables on

210 sport consumption patterns? There is some empirical evidence that women are more likely to be engage in aerobic and fitness than men (Warde, 2006). Other scholarly evidence, however, claims that unequal opportunities impinge on the ability of women to participate in a wide range of sports (Roberts, 1999; Shaw, 1994). A patriarchal society that provides men with social power and status places women at a relative disadvantage, with more

215 limited work opportunities and little support for working mothers through state funded childcare (Shaw). Working women subsequently have less leisure time, with domestic and 
caregiving responsibilities limiting their breadth of leisure engagement and affording men greater opportunities (Mattingly \& Bianchi, 2003).

There are number of reasons to expect other stratification variables will influence the socio-economic makeup of each cluster type. Disengagement theory suggests that $\mathbf{2 2 0}$ increasing physical and social limitations may have an impact on sport engagement as individuals get older. Evidence from the leisure field suggests that experimentation in leisure activities is highest at younger ages (Iso-Ahola, Jackson, \& Dunn, 1994). Some scholars, therefore, suggest that younger age cohorts are more inclined to be omnivorous (Stichele \& Laermans, 2006), though some scholars disagree (Warde \& Gayo-Cal, 2009; 225 Van Eijck et al., 2002). Others argue that as individuals who are active get older, they replace former social roles with new ones and adapt their relationships and activities in ways that keep them engaged (Atchley, 1993). The physical demands of some sports may also act as a barrier to older age cohorts. Ethnicity may also have an impact, with racial and, indirectly, economic barriers restricting entry into exclusive sports. On the other hand, the $\mathbf{2 3 0}$ consumption of mass sports such as cricket is likely to be evident, as this particular sport represents an integral part of both Asian and Caribbean culture. Those individuals who are married with children may be more likely to have restrictions on their leisure time (Sullivan $\&$ Gershuny, 2004) or have different leisure experiences (family leisure) than those who are single or married without children (Downward et al., 2011). Home ownership and a number 235 of the geographical location measures are established proxies of affluence and, therefore, so we might expect that such individuals will consume either a diverse range or solely highbrow sporting activities. Those living in more deprived communities are expected to be less engaged or consume the more accessible popularized sports.

After providing an insight in to the socio-economic makeup of each sport's cluster, 240 the third part of the analysis provides a nuanced rigorous statistical evaluation of the subtle socio-economic differences between the active sports clusters. For instance, does the socioeconomic profile of the omnivorous cluster differ uniformly from other clusters by class and education or are there also other subtle significant differences (age, gender, marital status, home ownership and ethnicity) which vary by cluster? Are there similar statistically $\mathbf{2 4 5}$ significant differences between the other three ("fitness class," "lowbrow omnivores," and "highbrow") active sports' groups?

\section{Data and Methods}

Our analysis of sporting engagement in England used data drawn from the 2005-06 Taking Part Survey (TPS). The TPS surveyed 28,117 adults via face-to-face interviews about their 250 participation in sport and cultural activities. Households were drawn from the UK national postcode address file, and interviews were conducted with a randomly selected member of each household aged 16 or over. The survey asked if respondents had taken part in a number of sport activities in the last 12 months $(1=$ Yes, $0=$ No). This question measured actual participation as opposed to self-reported tastes for particular sporting activities. The $\mathbf{2 5 5}$ decision to examine participation rather than preferences reflects the available data in the TPS, which did not ask about tastes. The TPS also includes a range of socio-demographic variables that account for differential opportunities for participation in our multivariate model.

Cultural scholars have stressed the need to measure cultural consumption practices that $\mathbf{2 6 0}$ reflect distinctions between "mass"/"popular" culture and "elite"/"high" culture (Chan \& Goldthorpe, 2005). It is, therefore, essential that a wide variety of sports that represent a wide spectrum of the sporting field that cross cut the perceived symbolic boundaries of culture and sport are used in our modeling approach. A total of 29 sports from the data were used to 
TABLE 1 Participation in Different Sports (TPS 2005-06)

\begin{tabular}{lc}
\hline Activity & Percentage (\%) \\
\hline Swimming & 35 \\
Fitness & 27 \\
Cycling & 16 \\
Rackets & 11 \\
Football & 10 \\
Golf & 9 \\
Jogging & 7 \\
Adventure & 6 \\
Water Sports & 4 \\
Cricket & 4
\end{tabular}

265 represent ten sporting indicators: swimming (indoor and outdoor), general fitness activity (keep fit and aerobics, health, fitness, gym or conditioning activities), cycling, racket sports (tennis, badminton and squash), football (5-a-side and 11-a-side), golf, jogging and road running, adventure sports (including orienteering, rambling, hill trekking or backpacking and climbing/mountaineering), water sports (rowing, yachting or dingy sailing, canoeing,

270 windsurfing or boardsailing, waterskiing and other water sport), and cricket (see Table 1). Some indicators are more attached to the masses (football), while others are far more exclusive (racket sports, water sports and adventure sports).

All respondents were coded to the National Statistics Socio-Economic Classification (NS-SEC), which is used as the standard measure of occupational class in the cultural

275 consumption literature (Chan \& Goldthorpe, 2007; Savage, 2006). Educational attainment was used as an additional measure of stratification. In the TPS, education is coded to the six official National Vocational Qualifications levels (England), ranging from degree level to no qualifications. Along with social class and educational attainment, other variables included gender (female dummy variable), age (categorical variable including young, mid-

280 dle, middle/older and old age), ethnicity (categorical variable including white and four non-white categories: Black, Asian, Mixed, Chinese and other) and marital status (categorical variable which differentiates between married/cohabited with and without children and includes single, lone parents and separated/divorced/widowed). The TPS also contains information about residential tenure (categorical variable whether the individual owns

285 his/her home, rents privately, or lives in council rented accommodation) and whether the individual lives in an urban or rural area. We also included geo-demographic classifications of small areas to examine whether sport consumption patterns are differentiated according to the socio-economic wellbeing of the local areas in which they live. Here the TPS survey respondents' addresses have been placed in a geo-demographic classification (ACORN)

290 according to unit postcode residence (the smallest area unit available, containing an average of just 40 individuals). The ACORN classification has five categories differentiating residential clusters according to their households' socio-economic well-being into: Wealthy achievers, Urban prosperity, Comfortably off, Moderate means, and Hard pressed.

\section{Modeling Approach}

295 To examine the relationship between stratification and cultural consumption, it is vital not to operationalize sporting practices as a discrete set of variables but as a carefully constructed space of lifestyles (Bennett et al., 2009). Other cultural scholars have also stressed that cultural activities are part of the wider cultural makeup of individuals, and 


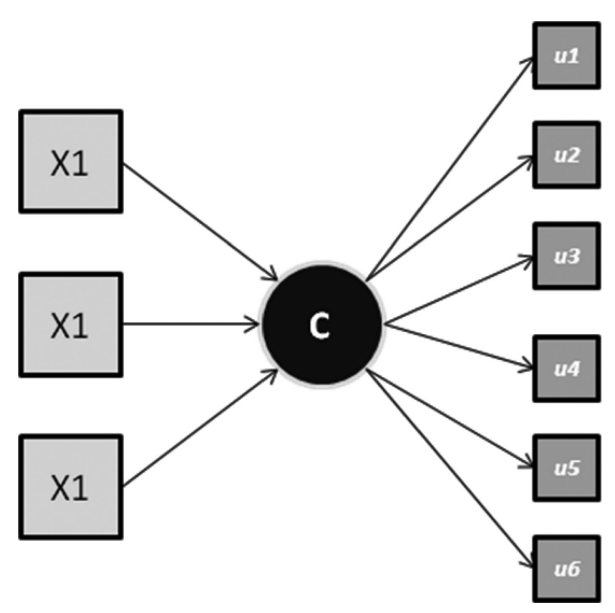

FIGURE 1 Path diagram - latent class analysis and MIMIC model.

rather than examine cultural items as discrete components, individuals should be grouped on observed patterns of consumption (Peterson \& Kern, 1996; Chan \& Goldthorpe, 2005; 300 Sintas \& Alverez, 2004; Van Eijck, 1999). Here we assume that there are relatively well defined types of sporting consumers who can be placed into lifestyle typologies based on their engagement in different sports. As a consequence we use a latent class analysis (LCA) modeling approach.

The LCA identifies typology groups or classes whose sporting behavior will be different $\mathbf{3 0 5}$ depending on membership of these classes. Individuals form sporting patterns based on consumption of sporting indicators " $\mathrm{u} 1$. . . u n" and can thus be assigned to different levels of a latent variable (class $\mathrm{C}$ in Figure 1). From this, it is possible to identify different types of sports consumers. LCA usually assumes local independence and estimates two essential parameters, latent class probabilities (the probability of an individual being in a particular $\mathbf{3 1 0}$ level or lifestyle typology) and conditional probabilities. Conditional probabilities are akin to factor loadings and are the probabilities of an individual in class t of the latent variable $\mathrm{C}$, being in a particular level of the observed variable (Magidson \& Vermunt, 2004). The LCA is traditionally termed the measurement part of the model.

In a latent class model, the standard chi squared measurement $\left(\mathrm{L}^{2}\right)$ can be unreliable 315 because of the number of sparse cells in the model. We therefore use alternative measures to determine the goodness of fit, including the Bayes Information Criterion (BIC), the Akaike Information Criterion (AIC), and the Consistent Akaike Information Criterion (CAIC). These measures are used because they weight both model fit and parsimony and are useful to compare models. The most widely used and statistically robust is the BIC where a model $\mathbf{3 2 0}$ with a lower BIC value is preferred over a model with a higher BIC value (Asparouhov \& Muthen, 2006).

A path diagram of the Multiple Indicator Multiple Cause (MIMIC) model is presented in Figure 1, where the subscript ' $u$ ' defines a categorical variable of interest (i.e., football participation, swimming, etc.), the circle encapsulating the ' $\mathrm{C}$ ' is an underlying latent class $\mathbf{3 2 5}$ measure (can include 1, 2, 3 . n classes). Thus the indicator variables are seen as arising from the unobserved latent class measure and are subject to measurement error. This is the measurement part of the model or LCA. The X variables influencing the latent class measure are independent control variables (i.e., social class, education). This second component adds structure to the model and allows investigation into the relationship between latent class 330 groups and a set of theoretically informed explanatory variables. In its simplest form, a 
TABLE 2 Results of the estimated cluster models, covariates included (TPS 2005-06)

\begin{tabular}{lccccc}
\hline Cluster & $\mathrm{L}^{2}$ & AIC(LL) & CAIC(LL) & BIC(LL) & df \\
\hline 1-Cluster & 11654.31 & 187984.79 & 187861.12 & 187999.79 & 1008 \\
2-Cluster & 2628.81 & 179071.97 & 178857.62 & 179097.97 & 997 \\
3-Cluster & 1650.00 & 178205.85 & 177900.81 & 178242.85 & 986 \\
4-Cluster & 1210.67 & 177879.20 & 177483.49 & 177927.20 & 975 \\
5-Cluster & 1079.57 & $\mathbf{1 7 7 8 6 0 . 7 9}$ & $\mathbf{1 7 7 3 0 2 . 3 9}$ & $\mathbf{1 7 7 9 1 9 . 7 9}$ & 964 \\
6-Cluster & 1001.39 & 177895.29 & 177318.20 & 177965.29 & 953 \\
7-Cluster & 971.461 & 177978.05 & 177329.27 & 178059.05 & 942 \\
\hline
\end{tabular}

MIMIC model is a simultaneous method of latent class analysis and multinomial regression, or logistic regression when there are only two levels of the latent variable (two classes).

\section{Results}

\section{Latent Class Analysis}

The initial process of LCA modeling is to determine the appropriate number of lifestyle types (classes) that exist in the population. In other words, the most parsimonious model that provides the best fit to the observed data. The results are shown in Table 2. Each goodness-to-fit measure, including the BIC statistics, reached its optimal point at a five-

340 cluster solution suggesting that this was the most appropriate model. ${ }^{3}$ The fit statistics clearly indicated that there were underlying consumers of sport who share similar response patterns.

\section{Profile of Sport Clusters}

The estimated size of the latent class clusters and the estimated conditional probability of

345 consuming each of the ten sport indicators given membership in a latent lifestyle cluster are reported in Table 3. Cluster 1 was populated by $9 \%$ of respondents and was distinguishable from its counterparts through their consumption of a wide range of sporting activities. Derived from the conditional probabilities, this group participated in all types of sports at a greater volume and range than any other latent class group. This cluster had preferences

350 that cross-cut the perceived hierarchy between more exclusive ("highbrow") and popular sports and had the highest propensity of participating in all types of sport that are measured here, especially swimming, fitness and cycling. We labeled this group "classic omnivores" because individual members had a breadth of sport consumption, which closely matches that identified in other scholarly work (Van Eijck \& Lievens, 2008; Peterson, 2005; Peterson 355 \& Kern, 1996).

Cluster 2, to which $27 \%$ of the respondents were classified, participated in fitness based activities. They were engaged in swimming, cycling, and general fitness and were inclined to participate in adventure and water sports. They appeared to distance themselves from the male dominated sports (football, golf and cricket). We labeled this group the "fitness class" because fitness is a key classifier of membership. Individual members of this group

\footnotetext{
${ }^{3}$ We decided to test alternative models and include local dependencies for some of the sporting items to determine whether we still got a five cluster solution. In all cases, we obtained the same cluster solution and, therefore, decided to continue with the original model as no violation of assumptions was evident.
} 
TABLE 3 Conditional probabilities of participating in a given sport

\begin{tabular}{|c|c|c|c|c|c|}
\hline $\begin{array}{l}\text { Class Size } \\
\text { Typology }\end{array}$ & $\begin{array}{c}\text { Cluster } 1 \\
0.09 \\
\text { Classic } \\
\text { Omnivores }\end{array}$ & $\begin{array}{c}\text { Cluster } 2 \\
0.27 \\
\text { Fitness } \\
\text { Class }\end{array}$ & $\begin{array}{c}\text { Cluster } 3 \\
0.10 \\
\text { Lowbrow } \\
\text { omnivores }\end{array}$ & $\begin{array}{c}\text { Cluster } 4 \\
0.13 \\
\text { Highbrow }\end{array}$ & $\begin{array}{c}\text { Cluster } 5 \\
0.41 \\
\text { Nonparticipants }\end{array}$ \\
\hline Swimming & 0.83 & 0.65 & 0.34 & 0.33 & 0.08 \\
\hline Fitness & 0.66 & 0.50 & 0.32 & 0.13 & 0.07 \\
\hline Cycling & 0.60 & 0.19 & 0.20 & 0.23 & 0.01 \\
\hline Rackets & 0.50 & 0.15 & 0.25 & 0.07 & 0.00 \\
\hline Football & 0.35 & 0.01 & 0.67 & 0.00 & 0.00 \\
\hline Golf & 0.35 & 0.03 & 0.16 & 0.27 & 0.00 \\
\hline $\begin{array}{l}\text { Jogging and } \\
\text { road running }\end{array}$ & 0.42 & 0.08 & 0.13 & 0.02 & 0.00 \\
\hline $\begin{array}{l}\text { Adventure } \\
\text { Sports }\end{array}$ & 0.33 & 0.06 & 0.02 & 0.09 & 0.00 \\
\hline Water Sports & 0.29 & 0.04 & 0.02 & 0.08 & 0.00 \\
\hline Cricket & 0.16 & 0.00 & 0.18 & 0.02 & 0.00 \\
\hline
\end{tabular}

also had a high probability of taking part in racket sports and water sports, as well as fitness based activities. Here we found evidence that attention to exercise or the cult of health for the purpose of fitness and body discipline, "exercise for exercise sake," had an affinity with this particular section of the population (Warde, 2006).

Cluster 3 shared similar omnivorous consumption patterns to cluster 2 in having a $\mathbf{3 6 5}$ moderate probability of participating in various exclusive and popular activities. While they shared similar probabilities of participating in fitness, cycling, racket sports, and jogging, members of cluster 3 also participated in the male dominated sports. We labeled this group "lowbrow omnivores" because they included individuals who combined a rather limited interest in sports associated with the middle and upper classes, with a greater affinity toward $\mathbf{3 7 0}$ popular sports (Stichele \& Laermans, 2006; Van Eijck \& Lievens, 2008). Members of this cluster did not readily consume exclusive sports that are perhaps indicators of privileged lifestyles.

Cluster 4 was populated by $13 \%$ of the survey population and was characterized as a high cultured sporting group, engaging in traditionally highbrow sports but not participating $\mathbf{3 7 5}$ in the more popularized activities (Bourdieu, 1978). The probability of members in cluster 4 being engaged in highbrow sports such as rackets and golf was $24 \%$ and $26 \%$, respectively. Members of this group also had a high probability of engaging in water sports (15\%) and adventure sports (15\%), both of which are sports associated with the higher social classes (Warde, 2006; Van Eijck, 2001). A similar group has been identified in other 380 cultural activities and labeled everything from "highbrow snobs" (Peterson \& Kern, 1996) to "traditional participants" (Stichele \& Laermans, 2006). Here we labeled members of this cluster "highbrows" to reflect their penchant for more highbrow/exclusive sporting activities.

Individual members of cluster 5 were exemplars of a non-active group who participated $\mathbf{3 8 5}$ very little in the sport field. They had an extremely low probability of taking part in any of the sporting activities even those that are deemed most popular. This cluster accounted for $41 \%$ of the survey population and was labeled "nonparticipants." The large number of individuals in this group is hardly surprising given that we were measuring active 
390 participation and not including watching sport on television or going to sporting events as a spectator. For the purposes of this article, we primarily focused on the active sports consumers.

\section{Socio-economic Characteristics of Sports Typologies}

After identifying conditional probabilities, the next step is to add the socio-economic 395 variables to the analysis. Table 4 presents the conditional probabilities of membership for each sport cluster by class, education, age, gender, ethnicity, marital status, urban-rural residence, and Acorn classifications. The findings provide an initial insight into the socioeconomic make-up of each sport cluster, and show that a variety of stratification variables play a significant role in determining the latent clusters beyond just class and education.

400 The "classic omnivore" group contained individuals predominantly from the higher social strata (managers in large corporations and higher professionals). Individual members of the "classic omnivore" group also tended to be highly educated (high probability of holding a degree), overwhelmingly white, male, predominantly aged $25-44$, mainly owneroccupiers of their homes, either single or married with children and have a higher probability

405 of living in urban areas. Members of the "classic omnivore" class also lived in the more prosperous neighborhoods ("wealthy achievers" and "comfortably off").

The "highbrow" group shared a number of similarities with the "omnivore" group. These individuals were from the higher social strata although a number were also from the middle classes (small employers and lower supervisory class). They had a broader range of

410 education attainment, although those with a degree (probability of .36) were still strongly represented in the group. Individuals in the highbrow group were also predominantly white, male, owner occupiers of their homes, were more likely to live in urban areas, and resided in the most prosperous neighborhoods. The primary difference between the "highbrow" group and the "classic omnivores" was age. The "highbrow" group was far more likely to

415 be made up of respondents from the older age cohorts. Consequently, they were more likely to be married and have no children living at home.

The "fitness class" consisted of individuals from a mix of social class backgrounds and educational achievement. Some respondents in this cluster were from higher social strata while others were from working class backgrounds. While those with a degree

420 were strongly represented in this group (probability of .42), members of this cluster also included respondents with average and lower levels of education. While respondents in the "fitness class" shared similar characteristics with the "omnivore' group"-similar age and ethnic profile, married with children and predominantly owner occupiers-they differed by gender and geographical location. Women were significantly more likely to be in this

425 cluster. Those in the "fitness class" were more likely to be lone parents and more likely to reside in urban than rural areas. They were also more likely to live in affluent neighborhoods, although a measurable proportion of this class came from "hard pressed" and more deprived neighborhoods.

The socio-economic makeup of the "lowbrow omnivore" group was the most distinct

430 from the other active sports' clusters. Members of this group were from the lower social strata, predominantly working class or students, had average and lower levels of education, and tended to be from a younger age cohort (16-24 years old). They were mainly male, predominantly white (although a significant small subset had a nonwhite ethnic profile), lived in rented accommodation, and were either single, married with children, or single

435 parents. They commonly resided in urban areas and were more likely to live in more deprived neighborhoods ("moderate means" and "hard pressed"). However, a small subset of this group resided in more affluent urban areas. 
TABLE 4 Conditional probabilities of belonging to the different classes by response category of the variables within the model (TPS 2005-06)

\begin{tabular}{|c|c|c|c|c|c|}
\hline Covariates & $\begin{array}{c}\text { Classic } \\
\text { Omnivores }\end{array}$ & Fitness class & $\begin{array}{l}\text { Lowbrow } \\
\text { omnivores }\end{array}$ & Highbrow & Nonparticipants \\
\hline Class Size & 0.09 & 0.27 & 0.10 & 0.13 & 0.41 \\
\hline \multicolumn{6}{|l|}{ Occupational Status } \\
\hline Large Employers* & 0.10 & 0.04 & 0.03 & 0.07 & 0.02 \\
\hline Higher Professional & 0.14 & 0.05 & 0.06 & 0.09 & 0.02 \\
\hline Lower Prof/Managerial & 0.29 & 0.26 & 0.15 & 0.22 & 0.12 \\
\hline Intermediate & 0.12 & 0.23 & 0.09 & 0.11 & 0.14 \\
\hline Small employers & 0.07 & 0.05 & 0.07 & 0.13 & 0.07 \\
\hline Lower supervisory & 0.07 & 0.07 & 0.11 & 0.14 & 0.11 \\
\hline Semi routine & 0.05 & 0.15 & 0.13 & 0.08 & 0.20 \\
\hline Routine & 0.02 & 0.07 & 0.14 & 0.10 & 0.21 \\
\hline Never worked & 0.01 & 0.02 & 0.03 & 0.00 & 0.07 \\
\hline Student and Other & 0.14 & 0.07 & 0.20 & 0.06 & 0.04 \\
\hline \multicolumn{6}{|l|}{ Education } \\
\hline Level $4 / 5$ & 0.63 & 0.42 & 0.29 & 0.36 & 0.14 \\
\hline Level 3 & 0.18 & 0.19 & 0.20 & 0.17 & 0.07 \\
\hline Level 2 & 0.13 & 0.20 & 0.24 & 0.21 & 0.15 \\
\hline Level 1 & 0.03 & 0.08 & 0.09 & 0.06 & 0.06 \\
\hline Other Qualifications & 0.01 & 0.03 & 0.03 & 0.04 & 0.06 \\
\hline No Qualifications & 0.02 & 0.09 & 0.15 & 0.17 & 0.53 \\
\hline \multicolumn{6}{|l|}{ Gender } \\
\hline Male & 0.70 & 0.11 & 0.88 & 0.84 & 0.38 \\
\hline Female & 0.30 & 0.89 & 0.12 & 0.16 & 0.62 \\
\hline \multicolumn{6}{|l|}{ Age } \\
\hline $16-24$ & 0.20 & 0.12 & 0.37 & 0.00 & 0.04 \\
\hline $25-44$ & 0.60 & 0.56 & 0.52 & 0.22 & 0.19 \\
\hline $45-64$ & 0.20 & 0.29 & 0.10 & 0.52 & 0.31 \\
\hline 65 plus & 0.00 & 0.03 & 0.01 & 0.27 & 0.45 \\
\hline \multicolumn{6}{|l|}{ Ethnicity } \\
\hline White & 0.95 & 0.87 & 0.65 & 0.97 & 0.84 \\
\hline Mixed & 0.01 & 0.02 & 0.03 & 0.01 & 0.01 \\
\hline Asian & 0.03 & 0.06 & 0.18 & 0.01 & 0.08 \\
\hline Black & 0.00 & 0.03 & 0.12 & 0.01 & 0.06 \\
\hline Chinese or other & 0.01 & 0.02 & 0.03 & 0.00 & 0.01 \\
\hline \multicolumn{6}{|l|}{ Tenure } \\
\hline Owner Occupied & 0.80 & 0.74 & 0.57 & 0.88 & 0.61 \\
\hline Social Rented & 0.03 & 0.14 & 0.21 & 0.06 & 0.30 \\
\hline Private Rented & 0.17 & 0.12 & 0.22 & 0.06 & 0.09 \\
\hline \multicolumn{6}{|l|}{ Marital Status } \\
\hline Married No Children* & 0.24 & 0.28 & 0.14 & 0.59 & 0.36 \\
\hline Married \& Children* & 0.35 & 0.32 & 0.32 & 0.15 & 0.11 \\
\hline Lone Parent & 0.09 & 0.17 & 0.16 & 0.01 & 0.07 \\
\hline Single & 0.26 & 0.14 & 0.35 & 0.12 & 0.12 \\
\hline Separated \& Divorced & 0.06 & 0.09 & 0.04 & 0.14 & 0.33 \\
\hline
\end{tabular}


TABLE 4 Conditional probabilities of belonging to the different classes by response category of the variables within the model (TPS 2005-06) (Continued)

\begin{tabular}{|c|c|c|c|c|c|}
\hline $\begin{array}{l}\text { Covariates } \\
\text { Class Size }\end{array}$ & $\begin{array}{c}\text { Classic } \\
\text { Omnivores } \\
0.09\end{array}$ & $\begin{array}{c}\text { Fitness class } \\
0.27\end{array}$ & $\begin{array}{c}\text { Lowbrow } \\
\text { omnivores } \\
0.10\end{array}$ & $\begin{array}{c}\text { Highbrow } \\
0.13\end{array}$ & $\begin{array}{c}\text { Nonparticipants } \\
0.41\end{array}$ \\
\hline \multicolumn{6}{|l|}{ Urban or Rural } \\
\hline Urban & 0.72 & 0.80 & 0.89 & 0.70 & 0.82 \\
\hline Rural & 0.28 & 0.20 & 0.11 & 0.30 & 0.18 \\
\hline \multicolumn{6}{|l|}{ Acorn Classification } \\
\hline Wealthy Achievers & 0.38 & 0.27 & 0.14 & 0.40 & 0.16 \\
\hline Urban Prosperity & 0.16 & 0.09 & 0.12 & 0.06 & 0.08 \\
\hline Comfortably Off & 0.30 & 0.31 & 0.27 & 0.33 & 0.27 \\
\hline Moderate Means & 0.09 & 0.14 & 0.22 & 0.11 & 0.16 \\
\hline Hard-pressed & 0.07 & 0.19 & 0.25 & 0.11 & 0.33 \\
\hline
\end{tabular}

*Large Employers and Higher Managerial; *Married/Cohabitation and no children; *Married/ Cohabitation and children.

Note. ${ }^{* *}$ UK education categories are equivalent to the following North American education categories: Level 1 = Less than high school (Grade 11 or less); Level 2 = High school diploma (including GED); Level 3 = Some College; Level 4 \& $5=$ Assoc Degree, Bachelor's degree, Some graduate training and Graduate or professional degree combined.

Finally, the nonparticipants' cluster included more working class and unemployed individuals. This cluster included a larger proportion of women, from the older age cohorts,

440 with fewer if any educational qualifications. They were either married with no children or more likely to be separated or divorced. They had a higher probability of being Asian or Black, and tended to live in socially rented (state aided) accommodation. Members of the nonparticipant group were also likely to live in urban deprived neighborhoods.

These findings provide an insight into the socio-economic makeup of each sport's cluster. While it may be possible to glean some headline socio-economic differences in membership between the clusters from the probabilities shown in Table 4, these cannot be substantiated without further rigorous statistical testing. Moreover, subtle socio-economic differences between the active sports' clusters are more difficult to validate statistically without regressing the clusters against each other. This is the focus of the next section.

\section{Differences Between Active Sport's Clusters}

Our evidence so far indicates that a variety of stratification variables determine the membership of a particular sports cluster. However, there were similarities among the four active sports' clusters (omitting nonparticipants). For instance, within each active sports cluster, individual members were predominately white, male (excluding the "fitness class") de-

455 gree holders (largest probability recorded for educational attainment in each active sport's cluster), owner occupiers, married with children, and live in urban areas. But were individual members of the "classic omnivore" cluster significantly more likely to be white, male, degree holders, own their home, etc., than those members of the other active sports' clusters? Are members of the "highbrow" group significantly more or less likely to have

460 broader levels of educational attainment than those in the "Fitness class"? To understand these subtle cluster differences, it is necessary to conduct further statistical testing. The different clusters are simultaneously regressed against each other and the key findings 


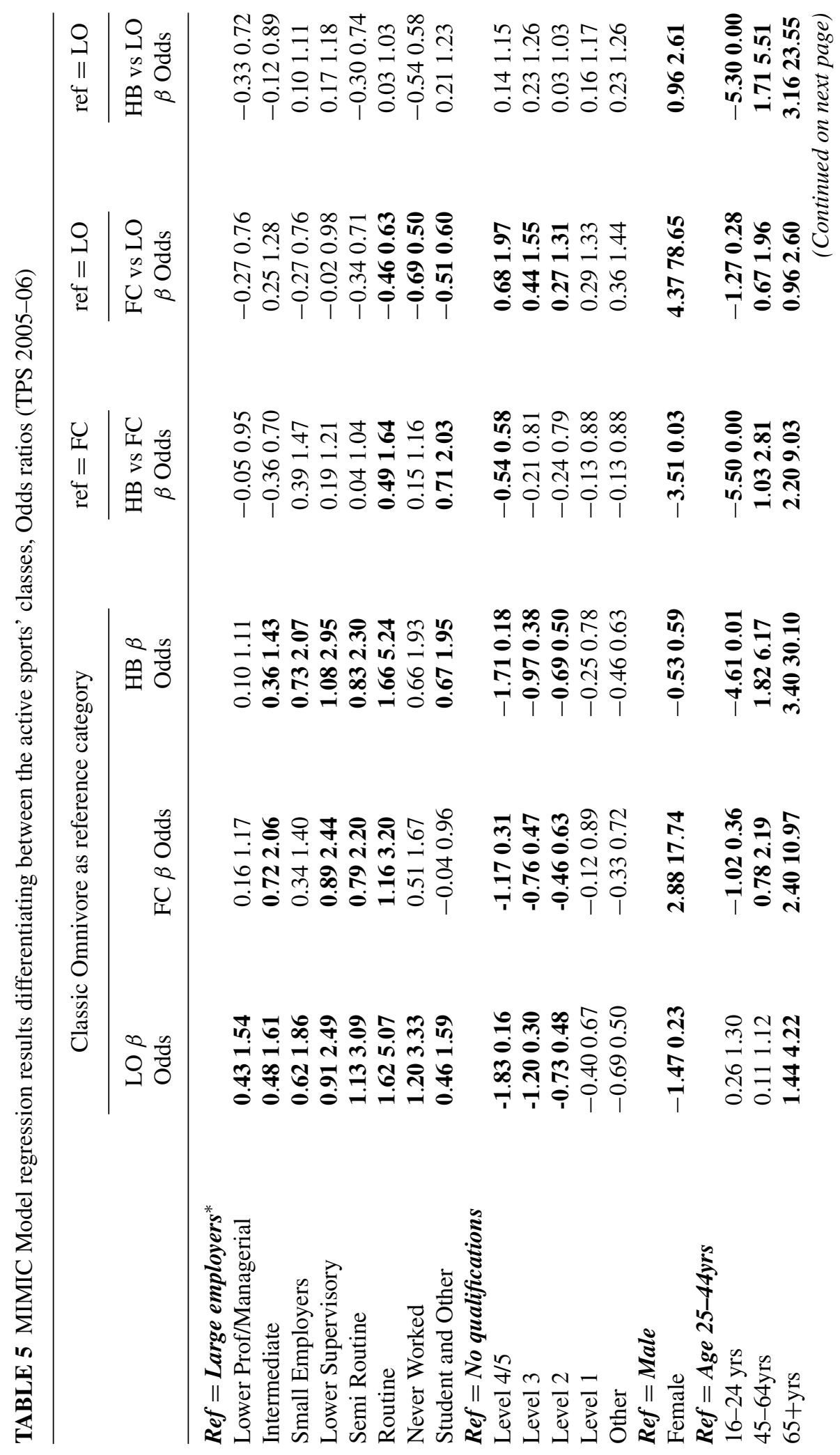




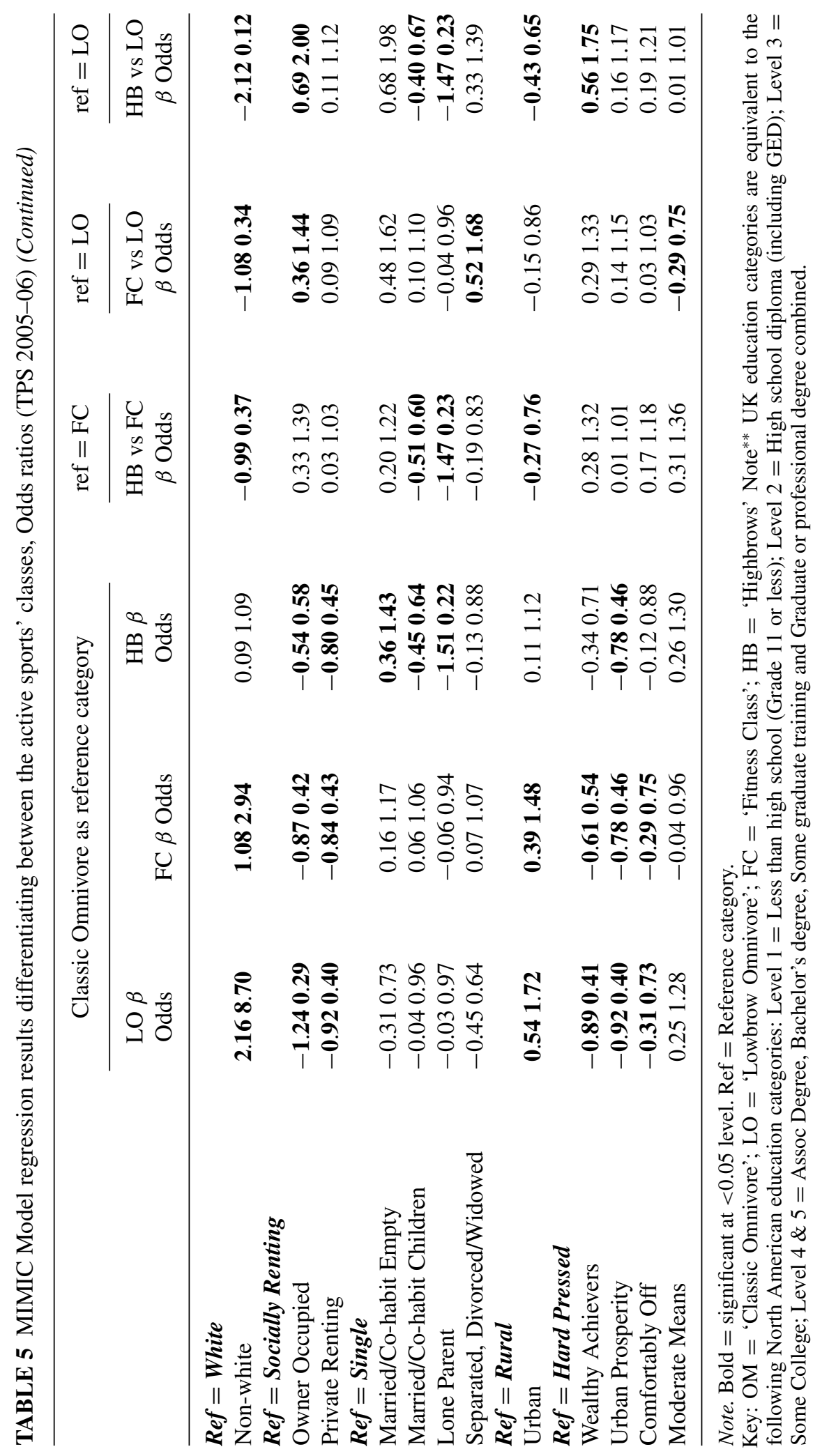


(those which are substantively interesting) are shown in Table $5 .{ }^{4}$ Here we focus on the active sports' clusters and report the unstandardized coefficients and log odds ratios for all the main socio-economic variables in each of the models for ease of interpretation. Table 5 contains the results of six regressions. The first three columns compare each of the three active sports clusters against the "classic omnivore" group where the latter is the reference category. Column 4 reports the regression results where the "highbrow" cluster is compared against the "fitness class" (as the reference category). Columns 5 and 6 detail any statistically significant socio-economic differences between two active sports clusters $\mathbf{4 7 0}$ ("highbrow" group and "fitness class") and the "lowbrow omnivores" where the latter is the reference category.

When compared with the "classic omnivore" group, all three of the active sports' latent classes were significantly more likely to be from middle or working class backgrounds and were less likely to have members with either a degree, further or secondary education qualifications. They were also significantly less likely to be homeowners or live in prosperous urban areas when compared against members of the "classic omnivore" group. This validates our earlier findings that "classic omnivore" members were more likely to be degree holders, come from the highest social class and generally live in affluent areas. Age was also important. There is evidence that "classic omnivore" members were younger, 480 although there was no significant youth difference between the "classic omnivore" and "lowbrow omnivore" groups. Yet all three active sports clusters were more likely to contain older members when compared with the "classic omnivores."

There were other subtle cluster differences between the "classic omnivores" and the other three active sports' clusters. When compared with members of the "classic omnivore" cluster, "lowbrow omnivores" and "highbrows" were significantly less likely to contain female members, whereas those in the "fitness class" were 17.7 times more likely to be female. Members of the "fitness class" and "lowbrow omnivores" group were 1.1 and 2.2 times more likely to contain individuals with a nonwhite ethnic profile than the "classic omnivore" group. By contrast, there was no statistical significant difference in the ethnic profile between "highbrows" and "classic omnivores". Finally, those who are married with no children were 1.4 times more likely to be in the "highbrow" group as opposed to the "classic omnivore" group, while the opposite is true for "lowbrow omnivores."

So while membership of the "classic omnivore" group can be distinguished uniformly from other clusters by class, education, homeownership, and living in affluent areas, there $\mathbf{4 9 5}$ are also other differences (i.e., age, gender, marital status, ethnicity) which vary by cluster. Are there similar differences between the other three ("fitness class," "lowbrow omnivores," and "highbrow") active sports groups? We address this question with the regression results in the final three columns of Table 5 .

In columns 4 and 6 of Table 5, the "highbrow" group was regressed against the "fitness $\mathbf{5 0 0}$ class" and "lowbrow omnivore" cluster, respectively. When compared with both these active sports' clusters, members of the "highbrow" group were significantly more likely to be from the older age cohorts, live in urban as opposed to rural areas, and were significantly less likely to be nonwhite, married with children, or single parents. Against the "lowbrow omnivore" group, neither social class nor educational attainment was significant drivers of $\mathbf{5 0 5}$ "highbrow" membership. The opposite was the case when comparing "highbrows" with

${ }^{4}$ In total, 20 regressions are simultaneously run (where each cluster is the reference category and simultaneously compared against the other four clusters). This is akin to a series of simultaneous multinomial regressions. For ease of interpretation, only the partial results from the MIMIC model are shown in Table 5 (the most substantively interesting). The full set of regression models is available from the authors on request. 
members of the "fitness class". Those in the "highbrow" group were 1.6 times more likely to be from the working class and two times more likely to be students than those in the "fitness class." Members of the "highbrow" cluster were also significantly less likely to

510 contain individuals with a degree than those in the "fitness class." When compared with "lowbrow omnivores," the "highbrow" group was significantly more likely to be female, homeowners, and live in affluent areas. When compared with the "fitness class," members of the "highbrow" group were significantly more likely to be male. So the importance of particular stratification variables on "highbrow" membership varied according to which active sports' cluster they were compared too. It is evident that class, educational attainment and gender mattered more for the "fitness class" than the "lowbrow omnivores" when compared with the "highbrow" group. This in turn suggests they will be distinguishing factors between these two clusters. This is borne out in the regression model (column 5 of Table 5) which compares membership of the "fitness class" against "lowbrow omnivores."

520 The regression results show that members of the "fitness class" were more likely to be female when compared with "lowbrow omnivores." These findings reflected the fact that "lowbrow omnivores" predominantly consumed male dominated sports such as football, cricket, and golf and participated less in fitness and swimming. Other factors also differentiate these two active sports' clusters. When compared with the "lowbrow

525 omnivores," those in the "fitness class" were roughly two times more likely to be highly educated and significantly less likely to have never worked, be from the routine working class, or have a nonwhite ethnic background. There were also distinctions by age, marital status, and tenure, with those in the "fitness class" between 2 and 2.6 times more likely to be from the older age cohorts, 1.6 times more likely to be married without children,

530 and 1.4 times more likely than "lowbrow omnivores" to be homeowners. In summary, both groups can be differentiated from each other by gender, but other factors also mattered. The "fitness class" contained respondents that were generally from high social strata, more affluent and highly educated than "lowbrow omnivores" and other sports clusters with the exception of the "classic omnivore" group.

\section{Conclusion}

This article addressed three key research questions. Given that we expected to identify different types of sports consumers, the first question focused on whether the sporting lifestyle types were similar or distinct from other cultural and leisure fields. Our findings largely corroborated recent scholarly work in these fields. Of the active sports' clusters,

540 there was evidence of a "classic omnivore" group whose members participate in all types of sports at a greater volume and range than any other cluster. Moreover, we identified partial omnivore types of sports' consumers, particularly a "lowbrow omnivore" group that consumed the more popular sports and had a minority interest in more exclusive activities. It is also possible to confirm recent scholarly evidence that there are distinctive "highbrow"

545 and omnivorous patterns. A small group of consumers participated exclusively in highbrow sports and largely ignored popularized sporting activities. The "fitness class" was more unique to sport than other fields. Our findings suggest that a relatively large section of the population who are engaged in sporting activities take exercise for the purpose of fitness and body discipline.

550 The second question focused on the socio-economic makeup of these identified sports clusters. Our findings suggest that the socio-economic make up of the sports clusters were largely analogous to those found in other cultural fields. The "classic omnivore" group was small in size and dominated by those from the higher social strata. It also included many individuals who were highly educated, homeowners, who lived in affluent areas, and were 
largely from the middle age cohort (Peterson \& Kern, 1996; Peterson, 2005). The existence 555 of a "highbrow" group that were older, white, well educated, and contained members from the higher social classes has also been recognized in other cultural fields (Peterson \& Rossman, 2007; Van Eijck, 2001). The "lowbrow omnivore" group contained respondents who were male, mainly from the lower social strata, and tended to have average or lower levels of education.

The "fitness class" was more distinctive from the other clusters mainly because gender was a key driver of cluster membership. Our evidence suggests that women tend to participate in a narrow set of sports, a likely consequence of unequal opportunities (Roberts, 1999), limited leisure time because of domestic care responsibilities, work opportunities, and state support for child care in England (Shaw, 1994). However, the sporting activities they do $\mathbf{5 6 5}$ participate in closely reflect their attitudes and objectives to fitness and exercise which differ from men (Warde, 2006). Body management and cultivating body shape through sport and exercise has long been regarded as a means by which individuals represent themselves and their values to others (Bourdieu, 1984). However, not only is gender more important but our evidence suggests that those from a broad-higher social strata, professional middle $\mathbf{5 7 0}$ class, and skilled working classes - rather than a distinct social background share a desire to engage in fitness and exercise for body management purposes and presentation.

The third question sought to examine the extent of more subtle socio-economic differences among the active sports clusters. Some of the findings validated earlier evidence. For instance, members of the "classic omnivore" cluster were significantly more likely to $\mathbf{5 7 5}$ be from the highest social class, have degrees, and generally live in affluent areas when compared with the other active sports clusters. However, there were some subtle differences among clusters.

Those in the "highbrow" group were more likely to be from the higher social strata, yet they were significantly less likely to be from this class when compared with the "clas- $\mathbf{5 8 0}$ sic omnivore" group. Moreover, among the higher social strata, there was no significant difference between membership in the "highbrow" group and the "fitness" cluster. "Highbrows" were significantly more likely to be from working class occupations than those in the "fitness class." With the "lowbrow omnivore" group, neither social class nor educational attainment was a significant determinant of "highbrow" membership. Members of the $\mathbf{5 8 5}$ "highbrow" group may therefore have consumed exclusive sporting activities, but those in the higher social strata did not necessarily consume exclusive sports. This finding questions the relationship between "highbrow" consumption and being from the higher social strata as depicted in other cultural fields (Peterson \& Rossman, 2007; Peterson, 2005; Van Eijck, 2001).

There were also other significant differences among the "fitness class," "highbrows, and "lowbrow omnivores." For instance, members of the "fitness class" were significantly more likely to be white, from the older age cohorts, and homeowners as opposed to living in public housing than "lowbrow omnivores." But the "fitness class" was significantly more likely to be female, from younger age cohorts, and contain members from a non-white ethnic $\mathbf{5 9 5}$ background than members of the "highbrow" cluster. While membership of the "classic omnivore" group can be distinguished uniformly—by class, education, homeownership, living in affluent areas-from the other active sports clusters, the significant differences between the remaining three clusters is more complex and less obvious than first appears.

While the focus of this article has specifically been on the active sports' consumers, 600 our findings show that more than two-fifths of individuals were nonparticipants. This is not surprising given the statistical evidence that sport participation appears to have stagnated not just in European countries but also in North America (Downward et al., 2011). While nonparticipation remains a considerable concern more generally for a nation's health and 
605 social policy, from a cultural and leisure perspective little has been done to identify whether there are different types of nonparticipant. Further research should also examine attitudes to sport to provide further insight in to why an individual participates or not. It may also provide more depth to our understanding of why certain individuals consume popular sports, highbrow sports, primarily fitness activities, and/or participate in all types of sports

$\mathbf{6 1 0}$ at a greater volume and range than these other existing clusters.

Our findings also ignore the importance of contextual effects, how they mediate social life, not only through social interaction and other macro-level forces but also how participation in the leisure field is enhanced through a sense of belonging or place (Widdop \& Cutts, 2012). If beliefs, attitudes, and expectations are socially constructed,

615 then any form of sports' participation will be influenced by place, not only through the interaction with others they reside with or share the same social world, but also through geographical location, as this social interaction must take place somewhere. Future work needs to address this current limitation and unpack the underlying mechanisms that occur in different contexts and that provide a crucial connecting tie between individual stratification and partaking in cultural and leisure activities. Finally, scholarly studies across the cultural and leisure fields largely look at tastes, spectatorship and/or participation, and sometimes knowledge, but rarely combine these to provide a comprehensive overview of the cultural genre. Data availability did not permit such a study in this case, but further research both nationally and cross-nationally combining both forms is re-

625 quired if we are to enhance our understanding of sport consumption patterns in the early 21 st century.

\section{References}

Asparouhov, T., \& Muthen, B. (2006). Robust chi square difference testing with mean and variance adjusted test statistics. Mplus Web Notes, No. 10.

630 Atchley, R. (1993). Continuity theory and the evolution of activity in later adulthood. In J. R. Kelly (Ed.), Activity and aging: Staying involved in later life (pp. 5-16). Newbury Park, CA: Sage.

Bennett, T., Emmison, M., \& Frow, J. (1999). Accounting for tastes: Everyday cultures in the life of Australians. Cambridge, England: Cambridge University Press.

Bennett, T., Savage, M., Silva, E., Warde, A., Gayo-Cal, M., \& Wright, D. (2009). Culture, class, distinction. London, England: Routledge.

Berghman, M., \& van Eijck, K. (2009). Visual arts appreciation patterns: Crossing horizontal and vertical boundaries within the cultural hierarchy. Poetics, 37(4), 348-365.

Bourdieu, P. (1978). Sport and social class. Thousand Oaks, CA: Sage.

Bourdieu, P. (1984). Distinction: A social critique of the judgment of taste. London, England: Routledge.

Chan, T. W. (2010). Social status and cultural consumption. Cambridge, England: Cambridge University Press.

Chan, T. W., \& Goldthorpe, J. H. (2005). The social stratification of theatre, dance and cinema attendance. Cultural Trends, 14(3), 193-212.

645 Chan, T. W., \& Goldthorpe, J. H. (2007). Social stratification and cultural consumption: Music in England. European Sociological Review, 23(1), 1-19.

Downward, P., Lera-Lopez, P., \& Rasciute, S. (2011). The zero-inflated ordered probit approach to modeling sports participation. Economic Modeling, 28(6), 2469-2477.

Eitle, T., \& Eitle, D. (2002). Race, cultural capital and the educational effects of participation in

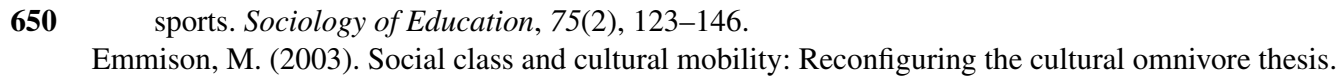
Journal of Sociology, 39(3), 211-230.

Erickson, B. H. (1996). Culture, class and connections? American Journal of Sociology, 102(1), 217-251. 
Holt, D. (1997). Distinction in America? Recovering Bourdieu's theory of tastes from its critics. 655 Poetics, 25(2-3), 93-120.

Iso-Ahola, S. E., Jackson, E., \& Dunn, E. (1994). Starting, ceasing, and replacing leisure activities over the life-span. Journal of Leisure Research, 26(3), 227-249.

Magidson, J., \& Vermunt, J. K. (2004). Latent class models. In D. Kaplan (Ed.), The Sage handbook of quantitative methodology for the social sciences (pp. 175-198; Vol. 10). Thousand Oaks, CA: 660 Sage.

Mattingly, M. J., \& Bianchi, S. M. (2003). Gender differences in the quantity and quality of free time: The U.S. experience. Social Forces, 81(3), 999-1030.

Mommaas, H. (1997). European leisure studies at the crossroads? A history of European leisure research. Leisure Sciences, 19(4), 241-255.

Mommaas, H., Van der Poel, H., Bramham, P., \& Henry, I. P. (1996). Leisure research in Europe: Methods and traditions. Oxon, England: CAB International.

Peterson, R. A. (1992). Understanding audience segmentation: From elite and mass to omnivore and univore. Poetics, 21(4), 243-258.

Peterson, R. A. (2005). Problems in comparative research: The example of omnivorousness. Poetics, 33(5-6), 257-282.

Peterson, R. A., \& Rossman, G. (2007). Changing art audiences: Capitalizing on omnivorousness. In B. Ivey \& S. Tepper (Eds.), Engaging art: The next great transformation of America's cultural life. New York, NY: Routledge.

Peterson, R. A., \& Kern, R. M. (1996). Changing highbrow taste: From snob to omnivore. American 675 Sociological Review, 61(5), 900-909.

Peterson, R. A., \& Simkus, A. (1992). How musical tastes mark occupational status groups. In M. Lamont \& M. Fournier (Eds.), Cultivating differences (pp. 152-86). Chicago, IL: University of Chicago Press.

Roberts, K. (1999). Leisure in contemporary society. Oxford, England: CABI Publishing.

Robinson, J. (1993). Arts participation in America: 1982-1992. Washington, DC: National Endowment for the Arts.

Savage, M. (2006). The musical field. Cultural Trends, 15(2), 159-174.

Shaw, S. M. (1994). Gender, leisure and constraint: Towards a framework for the analysis of women's leisure. Journal of Leisure Research, 26(1), 8-22.

Sintas, J., \& Alverez, G. E. (2004). Omnivore versus univore consumption and its symbolic properties: Evidence from Spaniards' performing arts attendance. Poetics, 32(6), 463-484.

Sonnett, J. (2004). Musical boundaries: intersections of form and content. Poetics, 32(3), 247264.

Stalker, G. (2011). Leisure diversity as an indicator of cultural capital. Leisure Sciences, 33(2), 81-102.

Stebbins, R. A. (1992). Amateurs, professionals, and serious leisure. Montreal, Canada: McGillQueen's University Press.

Stempel, C. (2005). Adult participation sports as cultural capital. International Review for the Sociology of Sport, 40(4), 411-432.

Stichele, A. V., \& Laermans, R. (2006). Cultural participation in Flanders: Testing the cultural omnivore thesis with population data. Poetics, 34(1), 45-64.

Sullivan, O., \& Gershuny, J. (2004). Inconspicuous consumption: Work-rich, time-poor in the liberal market economy. Journal of Consumer Culture, 4(1), 79-100.

Taks, M., Renson, R., \& Vanreusel, B. (1995). Social stratification in sport: A matter of money or 700 taste? European Journal of Sport Management, 2(1), 4-14.

Thrane, C. (2001). Sport spectatorship in Scandinavia: A class phenomenon? International Review for the Sociology of Sport, 36(2), 149-163.

Van Eijck, K. (1997). The impact of family background and educational attainment on cultural consumption: A sibling analysis. Poetics, 25(4), 195-224.

Van Eijck, K. (1999). Socialization, education, and lifestyle: How social mobility increases the cultural heterogeneity of status groups. Poetics, 26(5-6), 309-328. 
Van Eijck, K. (2001). Social differentiation in musical taste patterns. Social Forces, 79(3), 11631185.

710 Van Eijck, K., \& De Haan, Knulst, W. (2002). No more need for snobbism. Mens en Maatschappij, 77(2), 153-177.

Van Eijck, K., \& Lievens, J. (2008). Cultural omnivorousness as a combination of highbrow, pop and folk elements: The relation between taste patterns and attitudes concerning social integration. Poetics, 36(2-3), 217-242.

715 Van Eijck, K., \& Mommaas, H. (2004). Leisure, lifestyle and the new middle class. Leisure Sciences, 26(4), 373-392.

Warde, A. (2006). Cultural capital and the place of sport. Cultural Trends, 15(2-3), 107-123.

Warde, A., \& Gayo-Cal, M. (2009). The anatomy of cultural omnivorousness: The case of the United Kingdom. Poetics, 37(2), 119-145.

720 Warde, A., Wright, D., \& Gayo-Cal, M. (2008). The omnivorous orientation in the UK. Poetics, 36(2-3), 148-165.

Washington, R., \& Karen, D. (2001). Sport and society. Annual Review of Sociology, 27(1), 187-212.

White, P., \& Wilson, B. (1999). Distinction in the stands: An investigation of Bourdieu's 'habitus,' socio-economic status and sport spectatorship in Canada. International Review for the Sociology of Sport, 34(3), 245-264.

Widdop, P. A., \& Cutts, D. (2012). The Importance of place: A case study of museum participation. Cultural Trends, 21(1), 47-66.

Wilson, T. C. (2002). The paradox of social class and sports involvement: The roles of cultural and economic capital. International Review for the Sociology of Sport, 37(1), 5-16.

730 Wouters, C. (1998). How strange are our feelings of superiority and inferiority? Theory, Culture and Society, 15(1), 131-150.

\section{Appendix}

TABLE 1A Frequencies of Predictor Variables Used

\begin{tabular}{lc}
\hline Variables & Frequency $(\%)$ \\
\hline Occupational Status & \\
Large employers and higher managerial occupations & 3.8 \\
Higher professional occupations & 5.1 \\
Lower professional/managerial occupations & 18.7 \\
Intermediate occupations & 15.3 \\
Small employers and own account workers & 7.4 \\
Lower supervisory and technical occupations & 9.9 \\
Semi routine occupations & 15.1 \\
Routine occupations & 13.3 \\
Never worked & 3.9 \\
Student and Other & 7.6 \\
Educational Attainment & \\
Level 4/5 & 30.0 \\
Level 3 & 13.8 \\
Level 2 & 17.8 \\
Level 1 & 6.2 \\
Other Qualifications & 4.3 \\
No Qualifications & 27.9
\end{tabular}

(Continue on next page) 
TABLE 1A Frequencies of Predictor Variables Used (Continued)

\begin{tabular}{lc}
\hline Variables & Frequency (\%) \\
\hline Gender & \\
Male & 45.0 \\
Female & 55.0 \\
Age Groups & \\
16-24 & 10.2 \\
25-44 & 36.1 \\
45-64 & 30.3 \\
65plus & 23.3 \\
Ethnic Group & \\
White & 85.5 \\
Mixed & 1.6 \\
Asian & 6.9 \\
Black & 4.7 \\
Chinese or Other & 1.2 \\
Household Tenure & \\
Owner Occupied & 69.2 \\
Social Rented & 19.4 \\
Private Rented & 11.4 \\
Structure of Household & \\
Married/Co-habit empty & 33.7 \\
Married/Co-habit Children & 21.4 \\
Lone Parent & 10.1 \\
Single & 16.0 \\
Separated, Divorced or Widowed & 18.8 \\
Rural or Urban & \\
Rural & 20.2 \\
Urban & 79.8 \\
ACORN Classification & 29.2 \\
Wealthy Achievers & 14.5 \\
Urban Prosperity & 22.9 \\
Comfortably Off & 0.4 \\
Moderate Means & \\
Hard-pressed & \\
Unclassified & \\
\hline & \\
\hline
\end{tabular}

